\title{
Teaching analytical chemistry in China: past, present, and future perspectives
}

\author{
Sichun Zhang $•$ Xinrong Zhang
}

Published online: 28 May 2014

(C) Springer-Verlag Berlin Heidelberg 2014

\section{A brief history}

While there are references to the practice of chemical analysis in ancient Chinese times, the modern system of analytical chemistry was introduced into China in the late 19th century. Thanks to the Chinese chemist Shou Xu, who translated several chemical books from western countries, including two important books on analytical chemistry: Manual of Qualitative Chemical Analysis [1] and Quantitative Chemical Analysis [2]. The Chinese titles of the translated books were HUAXUE KAOZHI and HUAXUE QIUSHU. These two books, together with other books translated later by Chinese scientists, became the key textbooks for chemical analysis. For a long time, however, all textbooks related to the analytical chemistry in China were translated from western countries. Almost no textbooks on analytical chemistry were written by Chinese professors until the 1930s.

The earliest textbooks written by Chinese professors, which can be found in the library of Tsinghua University, are "Quantitative Chemical Analysis" by Yuanyu Cao in 1939 [3], and "Practically Quantitative Analytical Chemistry" by Xihong Sun in 1940 [4]. Beside the textbook of chemical analysis, the first textbook of instrumental analysis was written by Professor Hong Gao from Nanjing University in 1956 [5], although very few universities could offer this course to undergraduate students at that time. A big change happened in 1977: the Chinese opened the door to the world. The facilities for the analytical chemistry experiments have been greatly improved since then. Moreover, many professors in Chinese universities now have studied in western countries; therefore,

S. Zhang $\cdot X$. Zhang $(\triangle)$

Department of Chemistry, Tsinghua University, Beijing 100084,

China

e-mail: xrzhang@tsinghua.edu.cn the perfect combination of teaching analytical chemistry of China with that of western countries has been well achieved.

\section{Present developments}

Five chemistry courses are currently compulsory to earn a Bachelor degree in chemistry from Chinese universities: inorganic chemistry, organic chemistry, physical chemistry, analytical chemistry, and polymer chemistry. The teaching hours are 96 for analytical chemistry in the authors' university, including $32 \mathrm{~h}$ for chemical analysis and 64 for instrumental analysis. In fact, the teaching hours should be doubled, since we have an additional $96 \mathrm{~h}$ for practical training in analytical experiments. Table 1 shows the teaching outline of analytical chemistry in the authors' university, which is similar to that of other universities in China.

Beside the required course of analytical chemistry described in Table 1, several extended courses closely related to analytical chemistry are also offered as non-required courses based on the specialties of professors in different Chinese universities. For example, a course in advanced analytical chemistry has been offered by a few of Chinese universities. Some other universities now offer specific advanced courses, such as separation sciences, molecular spectrometry or electrochemical analysis. Additionally, more and more professors now focus their research on the application of analytical chemistry in life sciences; therefore, the extended courses are offered by those professors in bioanalytical chemistry, including enzymatic analysis, nucleic acid analysis, as well as protein analysis. Environmental analysis is also offered by several universities, including the subjects of air pollutant analysis, water analysis, and soil analysis. Nanoscience is now a hot topic and some non-required courses are also offered by professors working on nanoparticle 
Table 1 Teaching outline of analytical chemistry in Tsinghua University

\begin{tabular}{|c|c|}
\hline Teaching outline & Content \\
\hline \multicolumn{2}{|l|}{ Introduction to analytical chemistry } \\
\hline \multicolumn{2}{|l|}{ Quality assurance and data handling } \\
\hline \multirow[t]{5}{*}{ Chemical equilibrium and titration } & Acid-base titration \\
\hline & Complexometric titrations \\
\hline & Potentiometric titrations \\
\hline & Gravimetric analysis \\
\hline & Precipitation titrations \\
\hline \multirow[t]{3}{*}{ Sample preparation and separation } & Liquid extraction \\
\hline & Ion exchange \\
\hline & Solid-phase extraction \& microextraction \\
\hline \multirow[t]{3}{*}{ Chromatography } & Gas chromatography \\
\hline & High-performance liquid chromatography \\
\hline & Supercritical fluid chromatography \\
\hline \multirow[t]{3}{*}{ Electrophoresis } & Gel electrophoresis \\
\hline & Capillary electrophoresis \\
\hline & Capillary electrochromatography \\
\hline \multirow[t]{4}{*}{ Electroanalytical chemistry } & Conductimetry \\
\hline & Potentiometry \\
\hline & Coulometry \\
\hline & Voltammetry \\
\hline \multirow[t]{3}{*}{ Atomic spectroscopy } & Atomic absorption \\
\hline & Atomic emission \\
\hline & Atomic fluorescence \\
\hline \multirow[t]{4}{*}{ Molecular spectroscopy } & UV/Vis absorption spectroscopy \\
\hline & Luminescence spectroscopy \\
\hline & Infrared spectrometry \\
\hline & Raman spectroscopy \\
\hline \multicolumn{2}{|c|}{ Nuclear magnetic resonance spectroscopy } \\
\hline \multirow[t]{2}{*}{ Mass spectrometry } & Molecular mass spectrometry \\
\hline & Inorganic mass spectrometry \\
\hline \multirow[t]{3}{*}{ Surface analysis } & X-ray photoelectron spectroscopy \\
\hline & Ultraviolet photoelectron spectroscopy \\
\hline & Auger electron spectroscopy \\
\hline Radiochemical methods & \\
\hline
\end{tabular}

characterization by spectroscopy, microscopy, and so forth. However, due to the imbalanced development of universities in China, these courses are largely dependent on the professors at different universities.

The teaching laboratories in China have been gradually developed in the past 30 years. In the early 1980s, the content of an experimental course in analytical chemistry was mainly chemical analysis, and focused on basic operational skills training, identification of ions, titration, and gravimetry. Demonstration experiments predominated laboratory courses in analytical chemistry. A dozen students gathered together to watch the operation of the analytical instrument by the teacher. The students had little chance to operate the instrument themselves. Also, only few experiments were provided for the student, such as spectrophotometry, potentiometric or polarographic analysis, gas chromatography, and atomic absorption. This situation has been changing since the early 1990s. Practical training for experiments is considered to be one of the most important issues for teaching analytical chemistry. Most universities have devoted sufficient hours to undergraduate students for the experiments. Traditional experiments such as gravimetry and titration still receive special attention because they are considered to be the most important training in the concepts of precision and accuracy. Experiments such as electrochemical analysis; atomic, UV/Vis, and IR spectroscopy; as well as gas/liquid chromatography are fundamental 
experiments. All of the instruments are operated by the student themselves, instead of watching the operation of the teacher.

What we have to emphasize is that laboratory facilities have been greatly improved in the past 10 years due to increased government investments. The training laboratories of analytical chemistry for undergraduate students in the authors' university have been well equipped with some expensive instruments, such as mass, NMR and Xray photoelectron spectrometers for undergraduate students' experiments. To make full use of the potency of the laboratory facility and improve the efficiency of existing facilities, the teaching laboratories of analytical chemistry in the authors' department are open $24 \mathrm{~h}$ to strengthen the comprehension and use of virtual techniques, affording more practical opportunities for students. Figure 1 shows a corner of the teaching laboratory for analytical chemistry in Tsinghua University.

There are three units in analytical experiments to complete a full academic study at the chemistry department: basic experiments, comprehensive experiments, and exploratory experiments. The first two units of experiments are completed in strict accordance with the guidance of the teachers, but the third one, exploratory experiments, is designed and completed independently by the students. The students can arrange their time to carry out their experiments, since the laboratories are open for them $24 \mathrm{~h}$.

Most Chinese universities pay great attention to experimental skills training. The National Chemistry Experiment Competition has been regularly held in recent years. The ninth competition will be held at Lanzhou University in July 2014 (http://chem.lzu.edu.cn/ ArticleShow.asp?ArtID=935). The prospective scope includes inorganic chemistry, analytical chemistry (including chemical and instrumental analysis), organic chemistry (synthesis and characterization), and physical chemistry. Candidates are requested to combine their basic theory knowledge and comprehensive application ability. The contest examination questions will be closely related to chemical experiments and practical skills at the university level.

\section{Future perspectives}

As an important discipline of chemistry, analytical chemistry has been rapidly developed in the twentieth century and transformed from classical chemical analysis to modern instrumental analysis. With the emergence of new instruments, the teaching materials have been increased rapidly, making the textbooks thicker and extending the teaching hours. The reason for this situation is that the curriculum of teaching analytical chemistry currently is according to instrumental techniques and not scientific principles, as described by one of the present authors in a Chinese journal. Therefore, every time a new instrument is introduced, another chapter may be added to the textbooks, making the textbooks thicker and thicker with the development of instrumental technology. For example, there are already 34 chapters in "Principles of Instrumental Analysis" by D. A. Skoog et al. [6] and 29 chapters in "Analytical Chemistry" by K. A. Li et al. in Chinese [7]. Although many of the recently published textbooks in analytical chemistry are trying to compress the contents, however, from the present situation, the growing contents rather than elimination will become an irreversible trend. This is not a problem for a textbook that actually is a reference for students, but it would be a problem for professors to select the necessary teaching materials for their classes within the teaching hours available.

A question thus arises: is there any basic theoretical classification of analytical chemistry? If so, we might teach this course according to the theoretical system instead of according to instrumental techniques. The teaching hours may be greatly compressed, since a variety of instrumental techniques may belong to the same principle. This question has now been recognized by many professors in China and has become a hot topic of discussion by the Chinese analytical chemistry community in recent years. G. X. Xu, a Professor of Physical Chemistry in Peking University, at 90-years-old, has written an article entitled "Looking at Analytical Chemistry in the 21 st Century, from the Layman's Eyes". In his article, he proposed a theoretical classification according to the interaction of analytes with different physical fields. With this classification, six chapters may be suggested for a textbook of
Fig. 1 The teaching laboratory for analytical chemistry in Tsinghua University. Left, Chemical Analysis Lab. Right, Instrument Analysis Lab
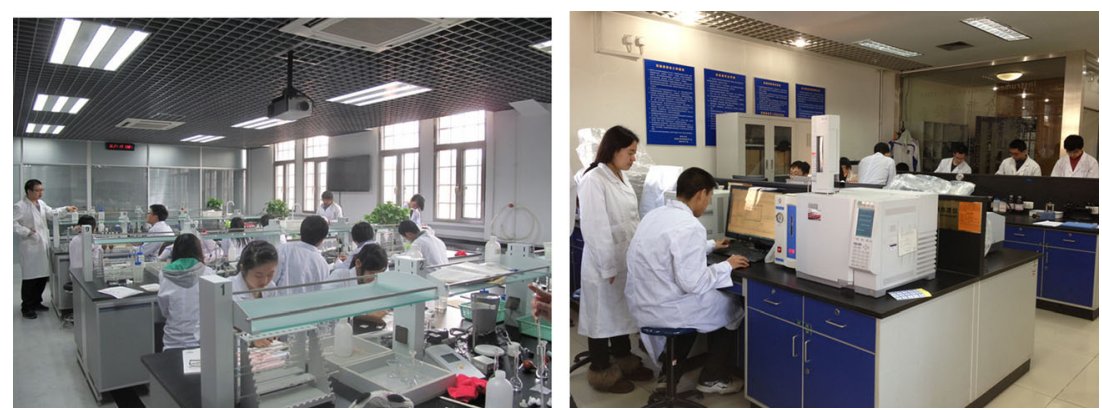
analytical chemistry. Another professor, X. Q. Guo, at Xiamen University suggested a new classification for teaching analytical chemistry according to the informatics classification with four basic knowledge modules. The suggestions proposed by the authors would be a solution to avoid the expansion of textbooks mentioned above.

This kind of research is worth encouraging because it would improve not only the teaching system, but also play an important role in the further development of scientific research in analytical chemistry itself. However, it should be pointed out that, although many professors are eager to take a personal interest in studying it, a perfect theoretical system for teaching analytical chemistry is obviously far from being established. It will be a great challenge to transform the teaching system for analytical chemistry from a technological to a scientific classification in future development, since analytical chemistry is essentially considered to be an applied science.

\section{References}

1. Johnson SW (1875) Manual of quantitative chemical analysis. Wiley, New York

2. Vacher A (1876) Quantitative chemical analysis. J.A.Churchill, London

3. Cao YY (1939) Quantitative chemical analysis. The Commercial Press, Beijing

4. Sun XH (1940) Practical quantitative analytical chemistry. Kaiming Bookstore, Beijing

5. Gao H (1956) Instrumental analysis. Higher Education Press, Beijing
6. Skoog DA, Holler FJ, Crouch SR (2007) Principles of instrumental analysis, 6th edn. Brooks/Cole, Thomson

7. Li KA (2005) Analytical chemistry. Peking University Press, Beijing

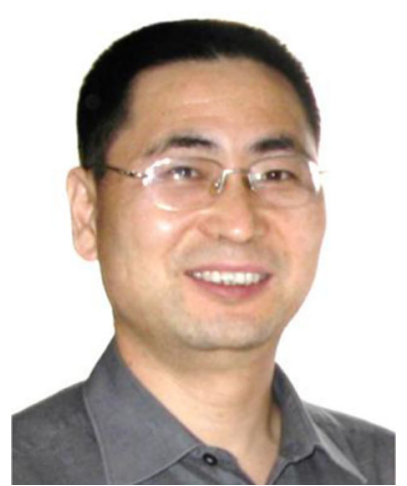

Sichun Zhang is an Associate Professor of Chemistry at Tsinghua University. He is also the Head of the Chemical Experiment Center of Tsinghua University. His research interests are focused on analytical instruments and their application.

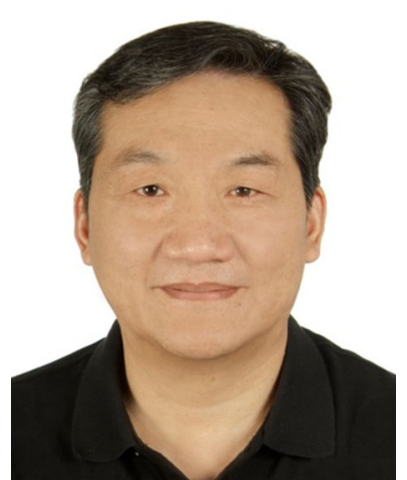

Xinrong Zhang is a Professor of Chemistry at Tsinghua University. His research involves mass spectrometry and luminescence analysis. He is now an RSC fellow, Associate Editor of Analytical Chemistry, and Advisory Board Member of Talanta and Analyst. $\mathrm{He}$ has been teaching analytical chemistry courses for over 25 years. 